\title{
Nuevas aportaciones a la reconstrucción virtual del Castillo de Aguilar de la Frontera (Córdoba)
}

\author{
Francisco Cabezas Pérez ${ }^{1}$ y Carmen Carbajo Cubero ${ }^{2}$ \\ 1 Técnico de Cultura del Ayuntamiento de Aguilar de la Frontera. Córdoba. España. \\ ${ }^{2}$ Arqueóloga del Ayuntamiento de Aguilar de la Frontera. Córdoba. España
}

\begin{abstract}
Resumen
Desde el año 2009 se viene realizando un proyecto de investigación en el Castillo de Aguilar de la Frontera, que ba sacado a la luz nuevas estructuras que ban supuesto una serie de cambios considerables en la única reconstrucción virtual existente basta el momento, que ha propiciado una nueva interpretación de la morfologia de la fortaleza, que si bien se acerca más a la realidad de la construcción, está sujeta a futuras modificaciones, ya que la investigación aún continúa.
\end{abstract}

Con esta comunicación pretendemos mostrar las nuevas aportaciones a la reconstrucción virtual del Castillo a partir de los nuevos descubrimientos.

Palabras Clave: AGUILAR DE LA FRONTERA, CASTILLO, RECONSTRUCCIÓN VIRTUAL,

\begin{abstract}
Since 2009 has been conducting a research project at the Castle of Aguilar de la Frontera, which has brought to light new structures that have brought a number of significant changes in the existing single virtual reconstruction so far, that has led to new interpretation of the morphology of the fortress, but is closer to the reality of construction is subject to future modifications, as the investigation continues.
\end{abstract}

In this paper we intend to show the new additions to the virtual reconstruction of the Castle from new discoveries.

Key words: AGUILAR DE LA FRONTERA, CASTLE, VIRTUAL RECONSTRUCTION.

\section{Introducción.}

La primera reconstrucción virtual del Castillo de Aguilar fue presentada en la edición inicial de Arqueológica 2.0, con una comunicación de Carmen Madrid de la Fuente y Francisco Montes Tubío, que reflejaba el trabajo de reconstrucción fotorrealista tridimensional de esta fortaleza, a partir de los restos arqueológicos que se encontraban en superficie después de la investigación arqueológica llevada a cabo por Alberto León Muñoz, que ponían de manifiesto parte de la Sala del Homenaje y restos de muralla de la fase bajomedieval del castillo, espacios que se extendían por la zona norte de la planicie donde se ubica la fortificación.

Desde el año 2009 se viene realizando un proyecto de investigación que ha sacado a la luz nuevas estructuras que han supuesto una serie de cambios sustanciales en la reconstrucción virtual realizada, que igualmente han propiciado una nueva interpretación de la morfología de la fortaleza.

La reconstrucción virtual no se ha limitado a la fortificación, si no que ha insertado a la misma en el entramado urbanístico que debió tener la villa de Aguilar durante el siglo XV.

\section{Contexto Histórico - Arqueológico.}

El Castillo de Aguilar de la Frontera ha sido objeto de investigación arqueológica de forma intermitente, desde 1992 hasta 2010.

Desde el siglo XIX, el cerro en el que se emplaza ha despertado un gran interés entre eruditos, investigadores y viajeros, no solo por la magnificencia de sus elementos arquitectónicos, sino por la riqueza arqueológica del propio cerro, que dada su situación geográfica privilegiada, ha sido lugar de asentamiento humano desde la Prehistoria, hecho constatado por la cantidad de materiales arqueológicos encontrados en superficie.

Nos encontramos ante una fortificación cuya estructura va evolucionando en los diferentes periodos históricos, siendo el elemento más temprano conservado, una torre de época califal. En la actualidad, la actividad arqueológica en el Cerro del Castillo se centra en las estructuras construidas en las últimas décadas del siglo XV, siendo los resultados sorprendentes, al poner de manifiesto la monumentalidad de la fortificación.

El Castillo de Aguilar, como otras muchas fortificaciones de la Península Ibérica, ha sufrido un deterioro permanente, provocado por diversos factores, por una parte el abandono, debido a que su principal función, la defensiva, deja de tener sentido; por otra parte por su ubicación, que a pesar de estar 
dentro del casco urbano de la ciudad, ocupa un espacio periférico en el entramado de la población, al desarrollarse éste de espaldas al cerro en el que se emplaza la fortaleza, y por otra, y quizás el principal factor a tener en cuenta, por su uso como cantera durante el siglo XIX, que supuso el desmonte de gran parte de las estructuras.

Su situación, en el cerro más alto de los siete que conforman la superficie sobre la que se extiende la ciudad de Aguilar de la Frontera, propició que en la década de los años 40 siglo XX, se escogiese dicho lugar para la construcción de un depósito de abastecimiento de agua para la población, construyéndose posteriormente, en la década de los 70 , un segundo depósito, suponiendo ambas estructuras hidráulicas un daño irreversible para el yacimiento.

\section{Metodología de trabajo.}

Para lograr las imágenes virtuales del yacimiento ha sido necesaria una metodología minuciosa, consistente en primer lugar en la búsqueda de la documentación que existe referente a la fortificación, actividad paralela a la investigación arqueológica. Una vez excavadas las estructuras se procedió al levantamiento planimétrico, que constituiría el armazón del posterior modelado $3 \mathrm{D}$, culminado con el montaje multimedia.

La comparación con fortalezas similares a las de Aguilar, siguiendo el criterio de Carmen Madrid, ha permitido la elaboración de modelos didácticos que facilitaran la comprensión del edificio, adoptando soluciones esquemáticas para aquellas partes de las que se dispone escasa información.

\section{Nuevas Aportaciones arqueológicas.}

Durante la última campaña de excavación, iniciada en 2009, son numerosos los elementos arquitectónicos identificados, si bien es cierto que se conocía su existencia por encontrarse algunos de ellos parcialmente en superficie, otros eran totalmente desconocidos, como es el caso de la falsabraga o la torre sur. El descubrimiento de ambas estructuras ha permitido dotar al grabado de la Corte y Ruano de su cuestionada veracidad, ya que ambos aparecen reflejados en dicha representación pictórica. A continuación describimos someramente dichas estructuras:

"Falsabraga": se trata de una barrera o muro de refuerzo que se construye para aumentar la defensa del lugar. De morfología zigzagueante, consta de alambor y muro alzado. Conserva la base de ocho troneras dispuestas una por cada tramo de la estructura. El largo de la misma está por definir, ya que todavía no se han identificado los extremos, aunque sí el ancho que es de $2 \mathrm{~m}$. aproximadamente. El sistema constructivo, de encofrado de ripios y mortero bastardo revestido por un paramento de sillería, se adapta a la topografía del terreno.

"Foso": Se trata de un elemento excavado directamente en la roca madre del cerro. Su escasa profundidad, que apenas alcanza los 2 metros en su zona más profunda, y su forma irregular, nos invita a interpretar que se trata de una obra que no llegó a finalizarse.

“Torre este": es una torre de planta circular de unos 4 metros de diámetro que se encuentra parcialmente destruida por la construcción del depósito de agua circular construido en los años 70 .

“Torre sur": torre de planta circular anexa al lienzo de muralla, que posiblemente conecte con la torre de la Cadena. Se ha visto muy afectada por la construcción de una zanja de canalización vinculada al depósito de agua circular, así como por el depósito de agua rectangular que ha afectado al lado sureste de la torre; aún así, puede documentarse la planta de este elemento que supera los 5 metros de diámetro.

\section{Descripciones históricas y documentación gráfica.}

Desgraciadamente las descripciones históricas sobre el Castillo de Aguilar son muy escasas, lo que ha motivado el desconocimiento sobre este edificio hasta la actualidad.

La mayoría de la información, interesante y en algunos casos repetitiva, se limita a datos de carácter histórico sobre acontecimientos y personajes. Habitualmente, los más documentados son los grandes hechos históricos, tratando de manera superficial otros aspectos hoy de mayor interés por ser más desconocidos.

No se conocen descripciones medievales del castillo, ni tampoco modernas. Sólo las fuentes escritas a partir de mediados y finales del siglo XVIII, hacen alusiones que generalmente son difíciles de interpretar. Esto sucede con el Catastro de Ensenada, primer dato que se tiene sobre el edificio. Concretamente dice:

"Posee dicho excelentísimo el castillo y Fortaleza de esta villa que se compone de una Plaza de Armas quadrada, y gruessa, de bastante altura y sin Almenas, y en el zentro de dicha plaza ai dos piezas, la una vaxa, que se llama la Sala de Armas, y la otra llamada la Cozina, y en el zentro del, ai quatro torres esta rodeada de Murallas: tiene ochenta y dos varas de frente y treinta y zinco de fondo".

A finales del siglo XVIII se escribe una historia de Aguilar atribuida a López de Cárdenas, actualmente desconocida, de la que se extrae la información que ha trascendido gracias a los escritos del siglo XIX. Precisamente, la reseña más completa es la de La Corte y Ruano, en 1839, que cita como fuente de la descripción de Lope de Cárdenas de 1782.

Durante el siglo XIX, una historia local de Juan de Dios Franco y Areco, realiza descripciones más detalladas sobre algunos aspectos del castillo, aunque se llega a confundir lo que ve de lo que copia de autores anteriores. Por él se conocen detalles sobre todo de los personajes que vivieron e intervinieron en diversas obras del castillo. Este autor achaca a Gonzalo Fernández de Córdoba, hacia 1370, la construcción del edificio, una plaza de armas con tres torres y el refuerzo de las murallas de la villa.

Ya a finales del siglo XIX y principios del XX, Ramírez de Arellano escribe un artículo que recoge parte de la información conocida, mencionando el foso que rodeaba al antemuro que era conocido como "la cárcava".

Hacia los años treinta del siglo XX, otro autor local, José Varo de Castro, viene a repetir la información de los autores antiguos, señalando a López de Cárdenas como origen de la información.

Por las Actas Capitulares se conocen algunos detalles de la fortaleza, sobre todo relativos al uso del edifico para albergar 
tropas y como hospital a finales del siglo XVII; y, sobre todo, a los actos protocolarios de toma de posesión del alcaide del castillo, ceremonia que se celebraba aún cuando ya estaba derruido.
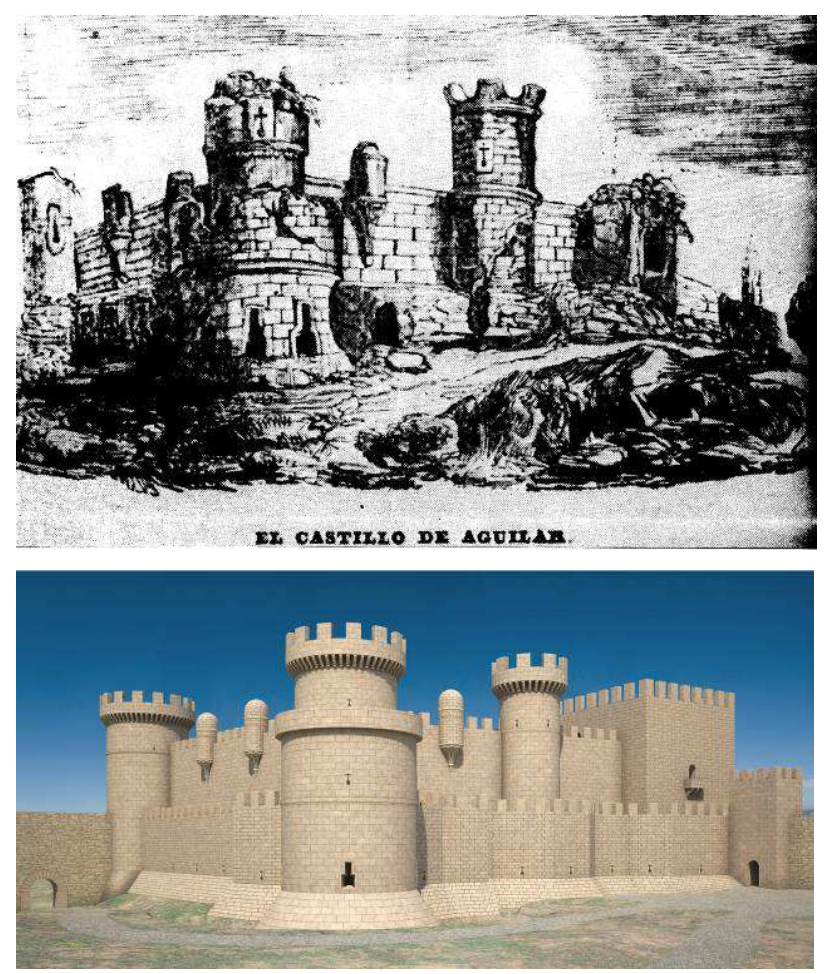

Figura 1. Comparativa del dibujo de la Corte y Ruano (arriba) y reconstrucción virtual (abajo)

Por esta información, muy dispersa, conocemos el nombre de algunas torres y dependencias, como es el caso del soportal de la puerta de entrada, la denominada torre Alta, la torre de la Campana y la torre del Homenaje, lo que viene a completar, junto con la torre de la Cadena, el conjunto de torres que rodeaban las murallas principales.

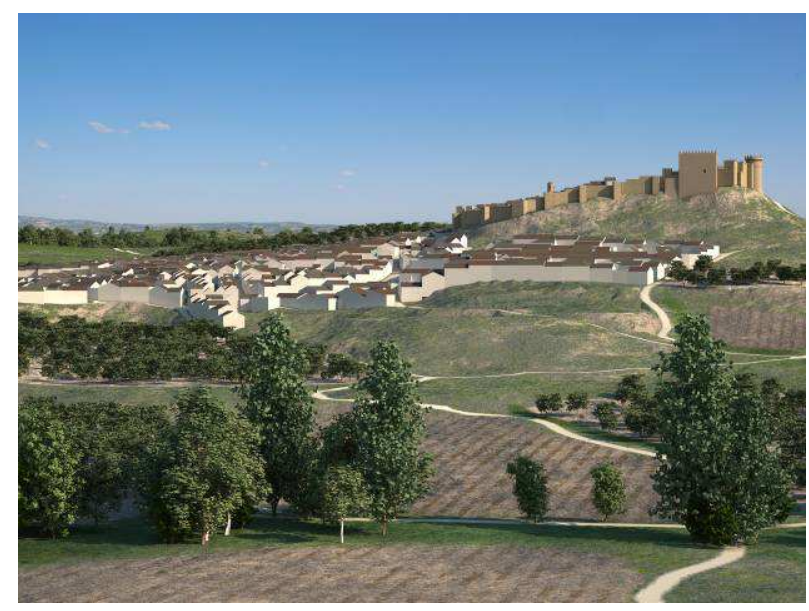

Figura 2.V ista virtual de la villa de Aguilar desde el norte
También, por alusiones decimonónicas se conoce la existencia de un patio de armas con corredores y pórtico a tres lados con columnas, una capilla, el salón del homenaje, el denominado salón de los tapices, las dependencias señoriales en la planta alta y las de la servidumbres en la parte baja, la sala de la guarnición, las caballerizas, la cocina o sala honda y una escalera de caracol que comunicaba este sitio con el patio de armas.

En cuanto al aspecto exterior, todos los autores coinciden en la rica decoración de los muros, con garitas, guirnaldas, cadenas, escudos... información que queda ratificada por las piezas decorativas interiores recuperadas en las excavaciones.

Sólo los trabajos arqueológicos están aportando la luz suficiente para conocer la distribución del castillo de Aguilar. Un edificio con obras de remodelación importantes a finales del siglo XV que no se llegó a concluir en la parte noroeste, conservando parte de las estructuras antiguas e incluyendo en su estructura algunos restos y dependencias de los siglos XIII y XIV.

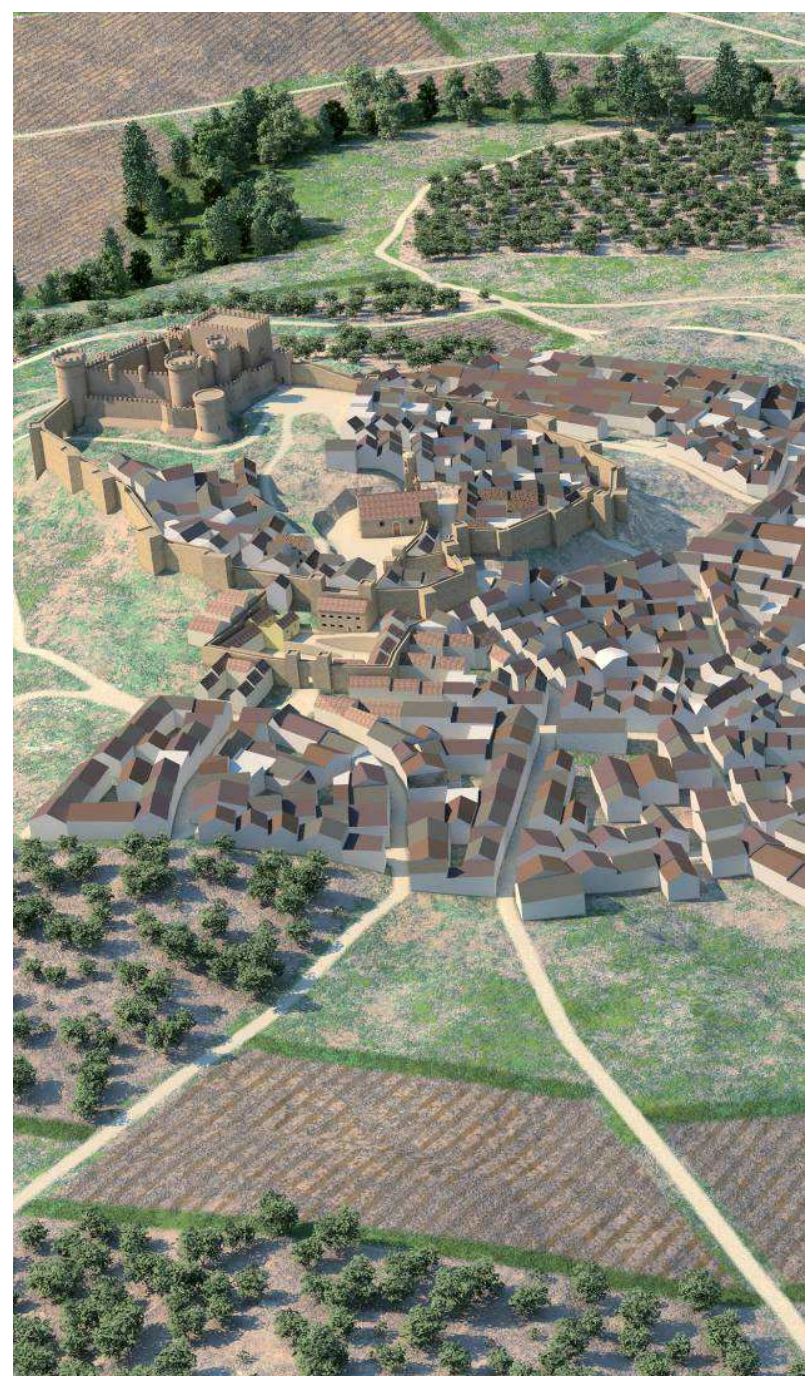

Figura 3.Vista aérea virtual de la villa de Aguilar desde el sur 


\section{Herramientas de diseño.}

Gracias a las descripciones, aún en su parquedad, y, sobre todo, al grabado de 1839, se ha podido realizar el modelo virtual basado en los datos sobre el terreno de las excavaciones de la planta, permitiendo su comprensión, promoviendo el interés por conocerlo y justificando el esfuerzo investigador realizado hasta el momento.

Para la recreación virtual, que abarca no sólo el edificio principal sino toda la villa de Aguilar a finales del siglo XV e imágenes retrospectivas de paisajes y poblados de la etapa Protohistórica, se ha recurrido a los servicios de una empresa especializada, Arketipo S.L., dentro del proyecto general de contenidos infográficos y audiovisuales del Centro de Interpretación del Paisaje y la Historia.

Algunas de las características técnicas de estos contenidos son las siguientes:

- Los audiovisuales se han realizado en formato HDV1080/720p, con el software Adobe Premiere /

Final Cut Pro y tienen una duración total de 55 minutos.

- El formato de los dos multimedia es Ejecutable PC, realizado con el software Adobe Director.

- La infografía está hecha con imágenes de hasta 8000 píxeles y secuencias de animación. El software empleado es Autodesk 3DStudio Max / Forest / GroundWiz / Vray.
A modo de detalle, la vegetación del entorno está compuesta por más de 20.000 árboles en algunas escenas. La precisión de la textura en el modelo ortofotográfico llega a $1 \mathrm{~m} /$ píxel, en toda la extensión de la provincia de Córdoba. La Villa de Aguilar contiene 1.104 viviendas posicionadas una a una en base a la referencia del callejero actual.

\section{Conclusiones.}

Para la difusión del patrimonio es fundamental una correcta comprensión y por tanto, una fiable interpretación de los restos arqueológicos objeto de estudio. El castillo de Aguilar de la Frontera, por el estado actual en el que se encuentra, se presenta como un reto para su difusión, ya que los restos conservados, muy afectados por diversas agresiones que ha sufrido a lo largo del tiempo, dificulta seriamente su interpretación por el visitante. Por este motivo, la reconstrucción virtual constituye una herramienta de vital importancia para su comprensión, más si cabe, si este trabajo infográfico viene acompañado de la necesaria documentación arqueológica, histórica y gráfica.

La reconstrucción presentada no pretende ser el culmen de un trabajo de investigación, sino un complemento a las labores científicas que aún se están desarrollando en torno a este yacimiento, que dada su naturaleza reversible, permite futuras modificaciones en función de los resultados que se vayan obteniendo.

\section{Agradecimientos}

Manifestar nuestro agradecimiento a Carmen Madrid de la Fuente, por realizar la primera reconstrucción virtual del Castillo de Aguilar de la Frontera, a Alberto León Muñoz, por hacer de este yacimiento el inicio de su andadura en el campo de la investigación arqueológica, ambos constituyen los principales pilares de un trabajo que aún continúa y que ha visto la luz gracias al inestimable trabajo de Juan José Jiménez Reina, diseñador gráfico, y a la empresa Arketipo, responsables de la infografía que actualmente permite una interpretación muy cercana de la realidad de esta fortificación en el siglo XV.

\section{Bibliografía}

ARCHIVO HISTÓRICO MUNICIPAL DE AGUILAR DE LA FRONTERA. Actas Capitulares (1500-1800).

CATASTRO DE ENSENADA (1757): Tomo I de seglares, inscripción nº 3. Archivo Histórico Municipal de Aguilar de la Frontera.

CORTE Y RUANO, Manuel de la (1849): "El castillo de Aguilar", en Semanario Pintoresco Español.

FERNÁNDEZ GONZÁLEZ, R. (1967): “El Castillo de Aguilar”, Boletin de la Real Academia de Córdoba no 87, Córdoba, pp. 65-124.

FRANCO Y ARECO, Juan de Dios (1849-1850): Estudio genealógico memorias de Aguilar, Ms.

GUTIÉRREZ, (1802): Noticias concernientes al mapa geográfico de Aguilar de la Frontera, Servicio Geográfico del Ejército, Arm. G TBLA. $6^{a}$, Carp. $3^{\mathrm{a}}$, $\mathrm{n}^{\circ}$ 266, en I.C.A. (Cartografía Histórica), $\mathrm{n}^{\circ}$ doc. 88-000420.

LEÓN MUÑOZ, Alberto (1998): El castillo de Aguilar de la Frontera: interpretación desde la arqueología. Ayuntamiento de Aguilar de la Frontera.

MADRID DE LA FUENTE, C., MONTES TUBÍO, F. (2010): "Reconstrucción fotorrealista tridimensional del castillo de Aguilar de la Frontera (Córdoba), en Virtual Archaeology Review, vol. 1, nº 1, pp. 115-119.

RAMÍREZ DE ARELLANO, Rafael (1983): Inventario Catálogo Histórico-Artístico de la provincia de Córdoba, (1ª ed. 1904). Córdoba.

VELASCO, Juan (1864-1865): Vista de Aguilar, acuarela. Biblioteca de Palacio Real de Madrid, mapa 24; ICA, 1988016059. 